\title{
Influence of defects on axial fatigue strength of maraging steel specimens produced by additive manufacturing
}

\author{
Daniele Rigon ${ }^{1, *}$, Giovanni Meneghetti ${ }^{1}$, Michael Görtler ${ }^{2}$, Daniele Cozzi $^{2}$, Wolfgang Waldhauser ${ }^{2}$ and Manuele Dabalà ${ }^{1}$ \\ ${ }^{1}$ University of Padova, Department of Industrial Engineering, via Venezia 1 - 35131 Padova, Italy \\ 2 Joanneum Research Forschungsgesellschaft mbH, Institute for Surface Technologies and Photonics, Niklasdorf Leobner Straße, 94 A- \\ 8712 Niklasdorf, Austria
}

\begin{abstract}
Nowadays many materials such as steels, aluminium and titanium alloys can be realised by powder bed solutions melting subsequently powder layers by means of a laser or electron beam (Laser Beam Melting - LBM and Electron Beam Melting - EBM). The microstructure realised by layer-by-layer solidification having high cooling rate cannot be considered isotropic. Therefore, the mechanical properties could be influenced by the building direction. Regarding maraging steel, the study of the influence of the building direction and the heat treatment on the static and axial fatigue strength has been investigated in a previous contribution. A large scatter of the fatigue test results was found because of the presence of detrimental surface and subsurface defects. The aim of this contribution is to present additional axial fatigue test results of maraging steel characterized by different build orientation and providing an analysis of the defects observed at the crack initiation area of the fracture surface.
\end{abstract}

\section{Introduction}

In PBF technologies, such as Selective Laser Melting SLM (or Direct Metal Laser Sintering DMLS) and Electon Beam Melting (EBM) layers of metal powder are subsequently melted by a laser or an electron beam source in order to obtain the part designed by a CAD software without the typical constraints of traditional manufacturing processes [1-4].

The main advantage of adopting an AM process is the possibility of producing components having customised and complex geometries. Indeed, from structural point of view, topological optimization is the key task in design for additive manufacturing for maximising the performance of the component for a given set of loading.

As reported in literature, the application of design for AM are currently reserved to aerospace, aeronautical and automotive fields because at the moment this new manufacturing process takes advantage in customized components with low production volumes due to the high process costs.

Nowadays, SLM process is relatively well developed in order to produce many alloys having comparable static mechanical properties with respect to wrought ones, as many contribution demonstrate [5-10].

Conversely, the critical point regarding the design of AM mechanical parts is the presence of defects which degrades the fatigue strength of the material [11,12]. Indeed, main causes of lower fatigue performance in AM parts were imputed to the surface finishing, the post heat treatment and the presence of defects currently unavoidable from the manufacturing process[13-15]. Typical defects that can be observed in SLM parts are incomplete fusion holes having irregular 3D shapes also known in literature as Lack Of Fusion (LOF). Other defects are pores with elliptical or spherical shape and crack-like defects. The formation mechanism of these defects is explained in [16].

For a design point of view, an accurate estimation of the fatigue limit, intended as the maximum stress that guarantee a fatigue life of a chosen number of cycles, cannot be done without taking into account the mechanics of the defects.

As well-known from [17], the fatigue strength is controlled by the defects having the maximum size and given the complex geometries of the LOF is appropriate to adopt the $\sqrt{\text { area }}$ parameter.

Therefore in some contribution [18], statistics of extreme values has been applied in order to estimate the maximum size of the defect starting from inspection by CT scanning.

The aim of this contribution is to add axial fatigue results of maraging steel produced by SLM to those previously published [19] and quantify the $\sqrt{\text { area }}$ of the defects present at the crack initiation zone of the fracture surface of the specimens by using a Scanning Electron Microscope (SEM).

\section{Materials and methods}

\subsection{Material and specimen's geometry}

Corresponding author: daniele.rigon.1@phd.unipd.it 
Table 1. Chemical composition of the powder adopted in the batch EOS and SISMA.

\begin{tabular}{|c|c|c|c|c|c|c|c|c|c|c|c|c|c|}
\hline Batch & $\begin{array}{l}\text { Fe } \\
(w t-\%)\end{array}$ & $\begin{array}{l}\mathrm{Ni} \\
(\mathrm{wt}-\%)\end{array}$ & $\begin{array}{l}\text { Co } \\
\text { (wt-\%) }\end{array}$ & $\begin{array}{l}\text { Mo } \\
\text { (wt-\%) }\end{array}$ & $\begin{array}{l}\text { Ti } \\
(w t-\%)\end{array}$ & $\begin{array}{l}\text { Al } \\
\text { (wt-\%) }\end{array}$ & $\begin{array}{l}\mathrm{Cr} \\
(\mathrm{wt}-\%)\end{array}$ & $\begin{array}{l}\mathrm{Cu} \\
(w t-\%)\end{array}$ & $\begin{array}{l}\text { C } \\
(w t-\%)\end{array}$ & $\begin{array}{l}\text { Mn } \\
\text { (wt-\%) }\end{array}$ & $\begin{array}{l}\text { Si } \\
(w t-\%)\end{array}$ & $\begin{array}{l}\text { P } \\
\text { (wt-\%) }\end{array}$ & $\begin{array}{l}\text { S } \\
(w t-\%)\end{array}$ \\
\hline EOS & balance & $17-19$ & $8.5-9.5$ & $4.5-5.2$ & $0.6-0.8$ & $\begin{array}{l}0.05- \\
0.15\end{array}$ & $\leq 0.5$ & $\leq 0.5$ & $\leq 0.03$ & $\leq 0.1$ & $\leq 0.1$ & $\leq 0.01$ & $\leq 0.01$ \\
\hline SISMA & balance & $17-19$ & $8.5-10$ & $4.5-5.2$ & $0.8-1.2$ & I & $\leq 0.25$ & I & $\leq 0.03$ & $\leq 0.15$ & $\leq 0.1$ & $\leq 0.01$ & $\leq 0.01$ \\
\hline
\end{tabular}

Two batches of cylindrical maraging steel specimens were considered in the contribution. The first batch $(\mathrm{E})$ is produced by a EOSINT M280 system, while the second one was provided by SISMA srl, that uses SISMA MYSINT 100 system to produce components made of maraging steel and other alloys. The material under investigation is maraging steel or also commonly known as $18 \mathrm{Ni} 300$. The chemical composition of powders and the process parameters adopted to produce fatigue testing samples are reported in Table 1 and 2, respectively.

The specimen's geometry designed for fatigue testing is shown in Fig. 1. For each batch the specimens were built with their axis oriented both at $0^{\circ}$ and $90^{\circ}$ with respect to the building direction that correspond to the translation of the platform which allows the deposition of the subsequent layer during the process. A schematic sketch of the orientation of the samples can be seen in Fig. 2. In addition, half of the total number of specimens were subjected to aging heat treatment for 6 hours at a temperature of $490^{\circ} \mathrm{C}$ and then air cooled.

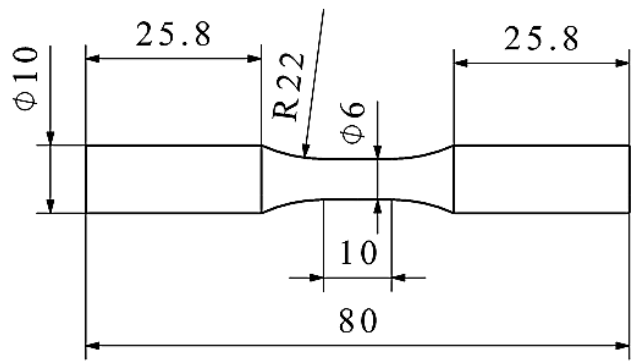

Fig. 1. Specimen's geometry.

For a clear comprehension of the results in the present contribution the nomenclature of the single test series is summarized in Table 3, where the prefix $\mathrm{E}$ and $\mathrm{S}$ are referred to EOS and SISMA respectively, $0^{\circ}$ and $90^{\circ}$ indicate the building direction and NT / T refer to Not heat-Treated and the heat-Treated condition, respectively.

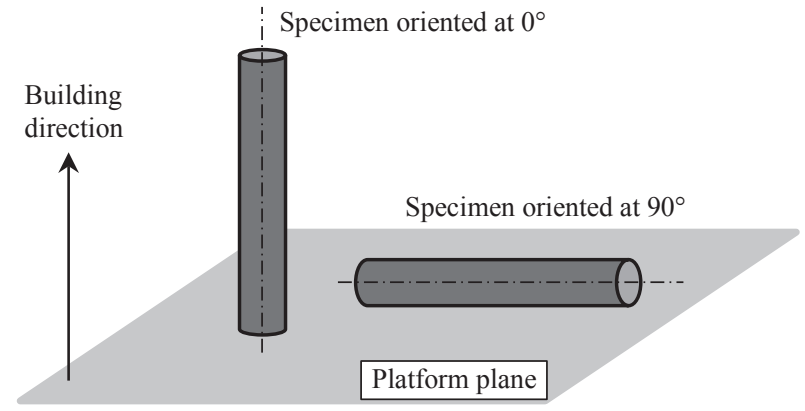

Fig. 2. Orientation of specimens' axis with respect to the building direction.

\subsection{Testing protocol}

Push pull, constant amplitude fatigue tests were carried out by using on the $\mathrm{S}$ batch and results were compared with the E batch previously tested [19]. All the specimens were polished by using progressively finer emery paper from grade 80 up to grade 800 .

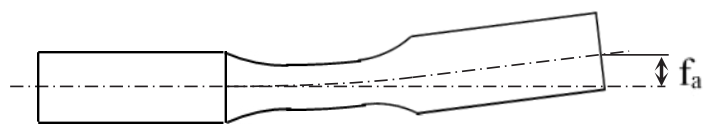

Fig.3. Deflection of the specimen's axis $f_{a}$ observed in [19].

Since it is known that in additive components the residuals stress induced by rapid cooling of the melted zone might cause geometrical distortion (as demonstrated in [19]), the gross section of each specimens were turned in order to reduce misalignments. Before machining, deflection of the specimen's axis $f_{a}$ (Fig. 3) was measured for all specimens.

The fatigue tests were carried out by using a servohydraulic SCHENCK HYDROPULS PSA 100 machine having a $100 \mathrm{kN}$ load cell and equipped with a TRIO

Table 2. Process parameters adopted to manufacture maraging steel specimens for fatigue testing.

\begin{tabular}{|l|l|l|l|l|l|l|l|}
\hline Batch & $\begin{array}{l}\text { Laser } \\
\text { power } \\
{[\mathbf{W}]}\end{array}$ & $\begin{array}{l}\text { Layer } \\
\text { thickness } \\
{[\boldsymbol{\mu \mathrm { m }}]}\end{array}$ & $\begin{array}{l}\text { Laser spot } \\
\text { diameter } \\
{[\boldsymbol{\mu \mathrm { m } ]}}\end{array}$ & $\begin{array}{l}\text { Laser scan } \\
\text { rate } \\
{[\mathbf{m m} / \mathbf{s}]}\end{array}$ & $\begin{array}{l}\text { Powder } \\
\text { dimension } \\
{[\boldsymbol{\mu \mathrm { m } ]}}\end{array}$ & $\begin{array}{l}\text { Temperature of } \\
\text { the platform } \\
{\left[{ }^{\circ} \mathbf{C}\right]}\end{array}$ & $\begin{array}{l}\text { Scanning } \\
\text { strategy }\end{array}$ \\
\hline EOS & 400 & 40 & 100 & Not provided & 60 & 40 & $\begin{array}{l}\text { Parallel } \\
\text { vector }\end{array}$ \\
\hline SISMA & 120 & 20 & 55 & 500 & $15 \div 45$ & Not provided & $\begin{array}{l}\text { Not } \\
\text { provided }\end{array}$ \\
\hline
\end{tabular}


Table 3. Nomenclature of the test series.

\begin{tabular}{|c|c|c|c|}
\hline Batch & $\begin{array}{l}\mathrm{N}^{\circ} \text { of } \\
\text { specimens }\end{array}$ & $\begin{array}{l}\text { Building } \\
\text { direction }\end{array}$ & $\begin{array}{l}\text { Heat } \\
\text { treatment }\end{array}$ \\
\hline E_AD_ $0^{\circ}{ }_{-} \mathrm{NT}$ & 12 & $0^{\circ}$ & NT \\
\hline E_AD_0 $0_{-}^{\circ} \mathrm{T}$ & 12 & $0^{\circ}$ & $\mathrm{T}$ \\
\hline E_AD_ $90^{\circ}{ }_{-} \mathrm{NT}$ & 12 & $90^{\circ}$ & NT \\
\hline E_AD_90 $0^{\circ} \mathrm{T}$ & 12 & $90^{\circ}$ & $\mathrm{T}$ \\
\hline $\mathrm{S} \_\mathrm{AD}{ }^{\circ} 0^{\circ} \mathrm{NT}$ & 10 & $0^{\circ}$ & NT \\
\hline $\mathrm{S}_{-} \mathrm{AD} \_0^{\circ}{ }_{-} \mathrm{T}$ & 8 & $0^{\circ}$ & $\mathrm{T}$ \\
\hline S_AD_90 & 10 & $90^{\circ}$ & NT \\
\hline S_AD_90 $0_{-}^{\circ} \mathrm{T}$ & 10 & $90^{\circ}$ & $\mathrm{T}$ \\
\hline
\end{tabular}

Sistemi RT3 digital controller. The load frequency was set in the range between $10 \mathrm{~Hz}$ and $30 \mathrm{~Hz}$, depending on the applied load level.

After fatigue testing the fracture surfaces were observed by means of Scanning Electron Microscope (SEM) in order observed the cause of failure at the crack initiation point. In particular, since the LOFs are the most frequent and often more detrimental in terms of fatigue strength, the $\sqrt{\text { area }}$ were measured following the guide line reported in [17].

\section{Measurements}

\subsection{Roughness}

In Fig.4 is reported a histogram of the $\mathrm{Ra}$ mean values measured on the surface of 5 specimens per test series along the longitudinal direction. It can be seen that all test series present a Ra value approximately $0.5 \mu \mathrm{m}$.

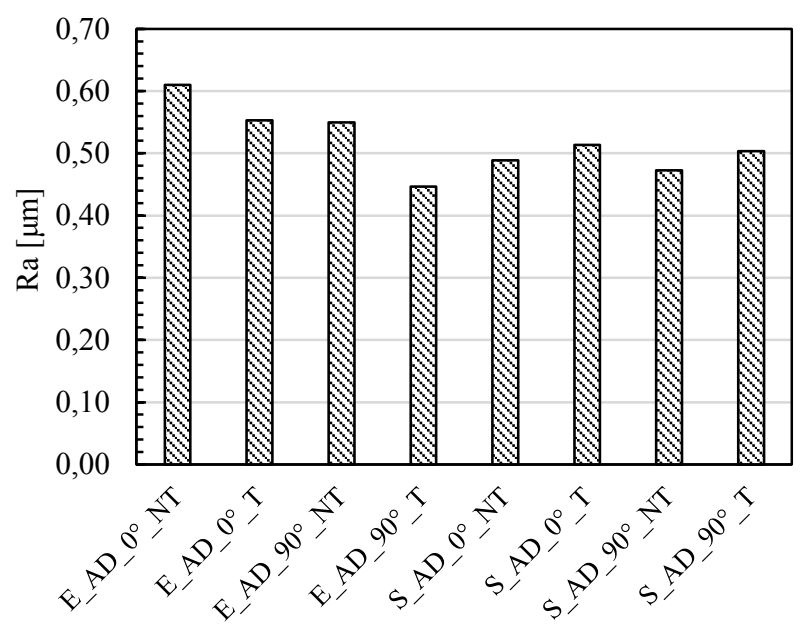

Fig. 4. Ra mean value for each test series.

\subsection{Geometrical distortion}

Geometrical distortion of each batch, in terms of deflection of the specimen's axis $\mathrm{f}_{\mathrm{a}}$, was measured, and the synthesis of the mean values is reported in Fig.5. In the previous work [19] deflection values were used for evaluating the mean stress that is caused by the machine gripping system. Contrary, in this contribution the gross section of specimens provided by SISMA srl, were turned in order to avoid mean stress state during fatigue testing, therefore the value of $f_{a}$ is reasonable negligible.

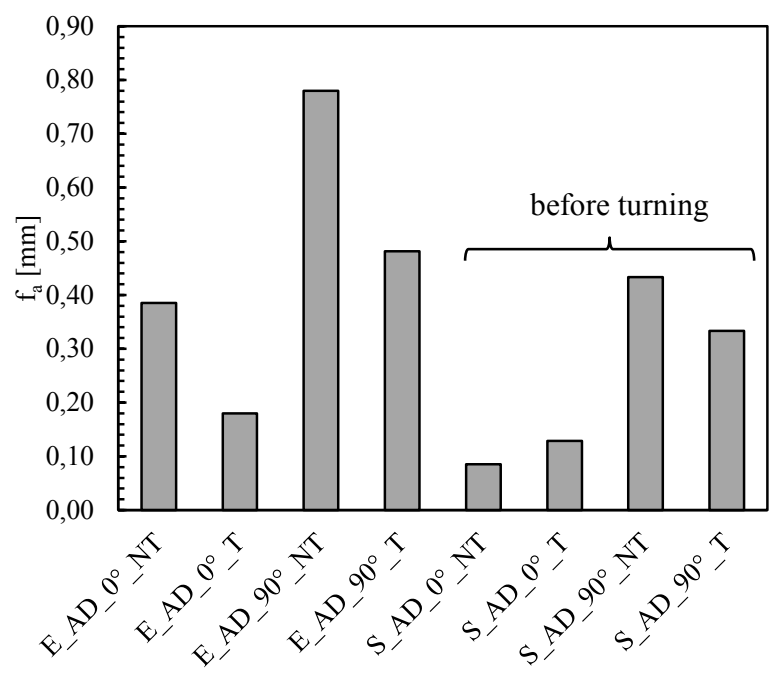

Fig. 5. Mean value of deflection $\mathrm{f}_{\mathrm{a}}$ for each test series.

\subsection{Hardness}

Micro-hardness (HV) was measured in one specimen per test series and the results are reported in Fig.6. Due to the aging hardening heat treatment the hardness of the is doubled with respect to the NT series. This was not observed in $\mathrm{S}$ batch, where it seems that the aging treatment has not been effective.

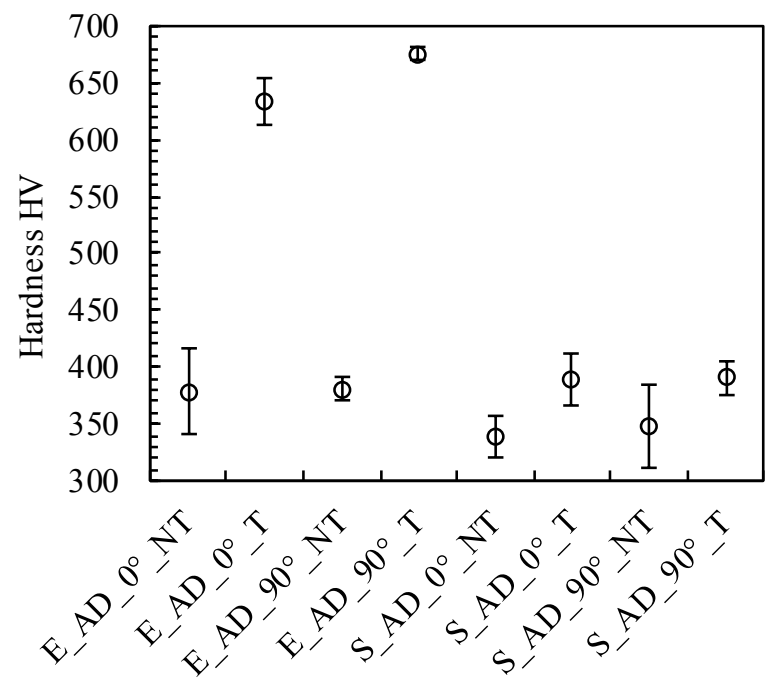

Fig. 6. Microhardness (HV) results for each test series.

\section{Results}

\subsection{Fatigue test results}

Fig. 7(a-d) show the fatigue test results in terms of nominal stress amplitude of the test series related to the 
a)

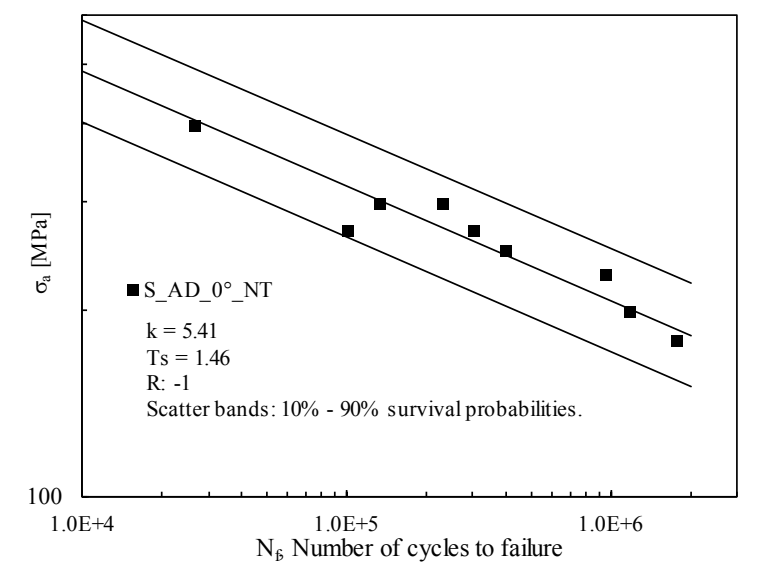

c)

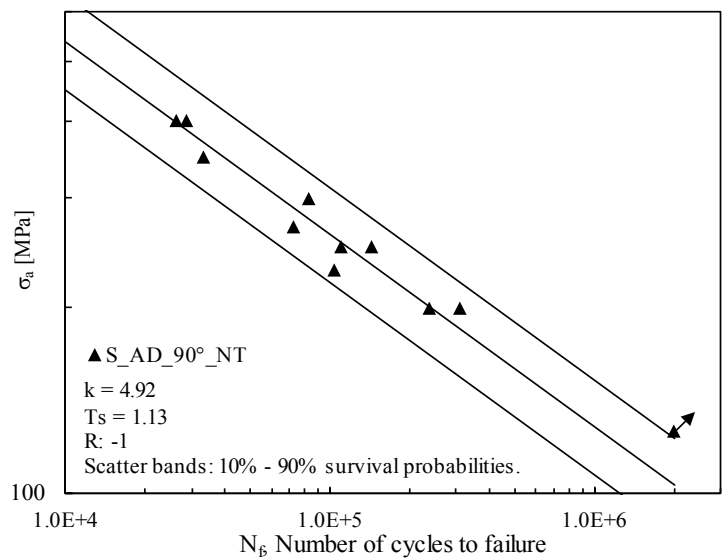

b)

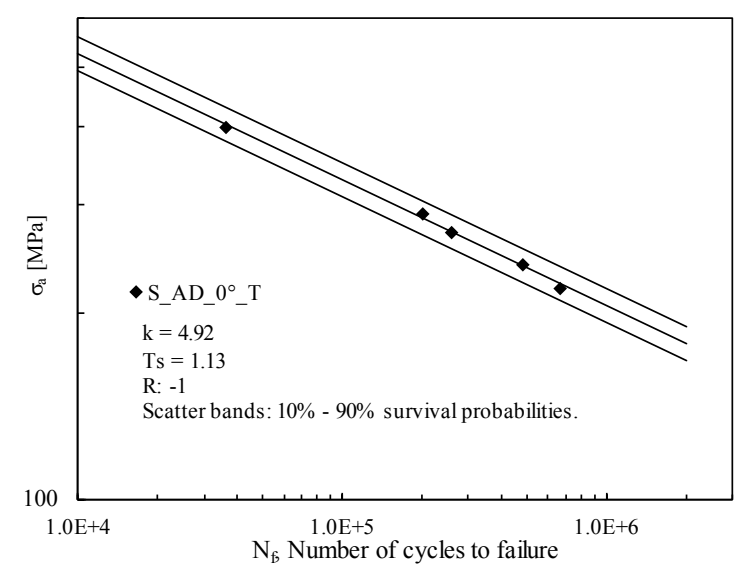

d)

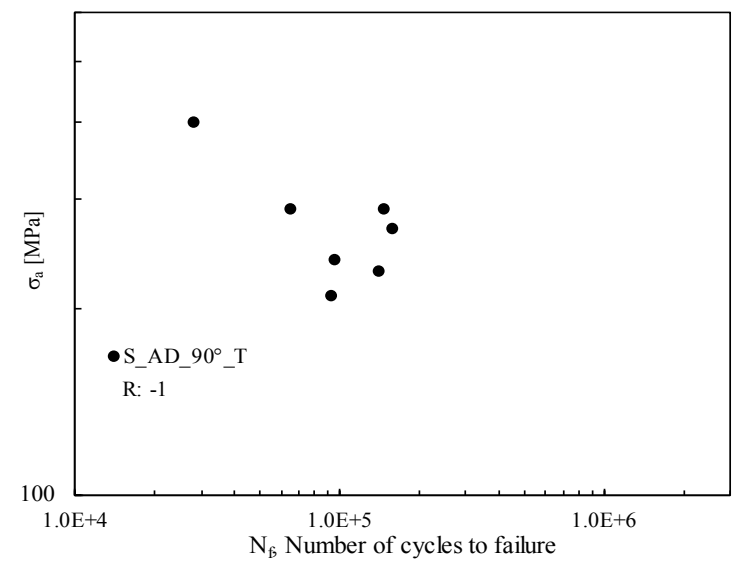

Fig. 7. Fatigue test results of the test series related to the (S) batch in terms of nominal stress amplitude.

(S) batch. The single scatter bands are referred to $10-$ $90 \%$ probability of survival obtained from statistical analysis of the fatigue data.

Since the fatigue test results of the (E) batch were affected by mean stresses, for a comparison purposes both (S) batch and (E) batch results have been reported in Fig. 8 in terms of SWT parameter. As a result of turning, the SWT value of the specimens of the batch $\mathrm{S}$ is simply the applied nominal stress amplitude.

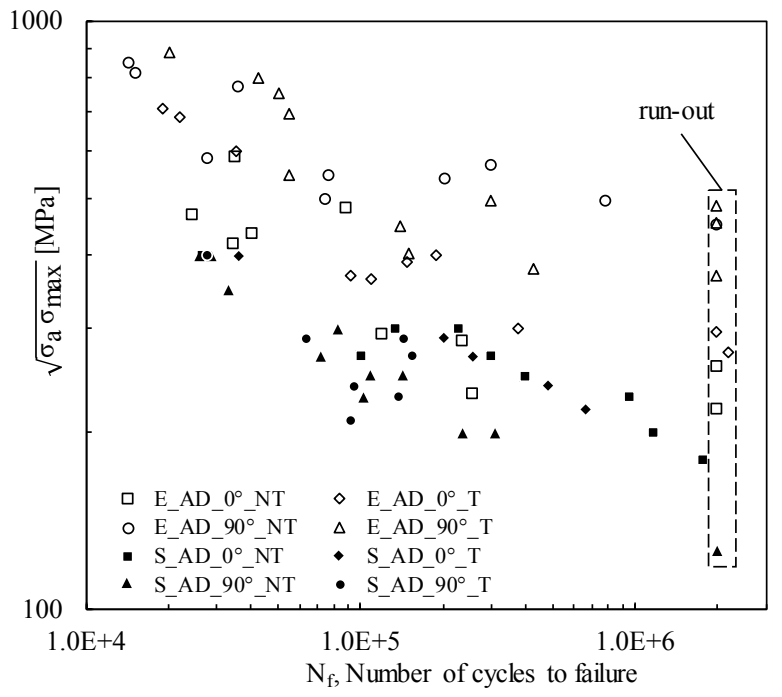

Fig. 8. Constant amplitude fatigue tests results of S-batch compared to E-batch already published in [X]. The S-batch results are considered without mean stress effect following the turning of the specimens' gross sections.

For all details of $\mathrm{E}$ batch results the reader is referred to [19].

\subsection{Fractography}

In Fig. 9 the available fracture surfaces of specimens $0^{\circ}$ oriented at the crack initiation point are shown. In agreement with results from the literature of the recent past, the cause to failure in AM components are LOFs, and such defects present irregular shapes. As reported in Fig. 9, the effective area adopted to evaluate the $\sqrt{\text { area }}$ parameter is highlighted by a red dotted line in each image. To choose the effective areas, suggestions reported in [17] were followed.

\section{Conclusions}

In this contribution, an experimental analysis of the defects that affect the fatigue behaviour of two batches of maraging steel specimens produced by additive manufacturing has been reported. 


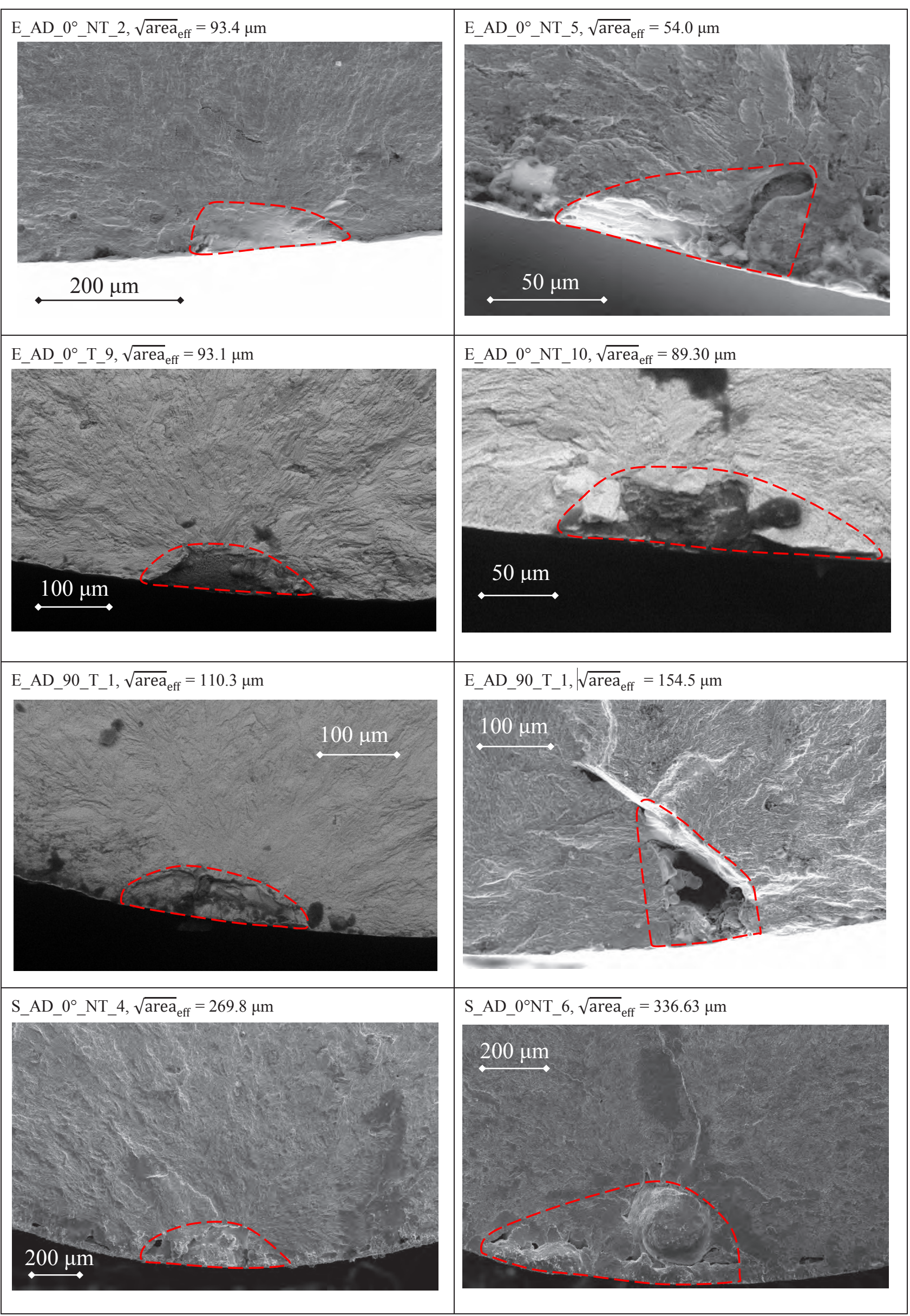

Fig 9. Examples of LOF at the crack initiation zone of the (E) and (S) batches. The $\sqrt{\operatorname{area}}_{\text {eff }}$ was estimated from the effective area highlighted by red dotted line. 


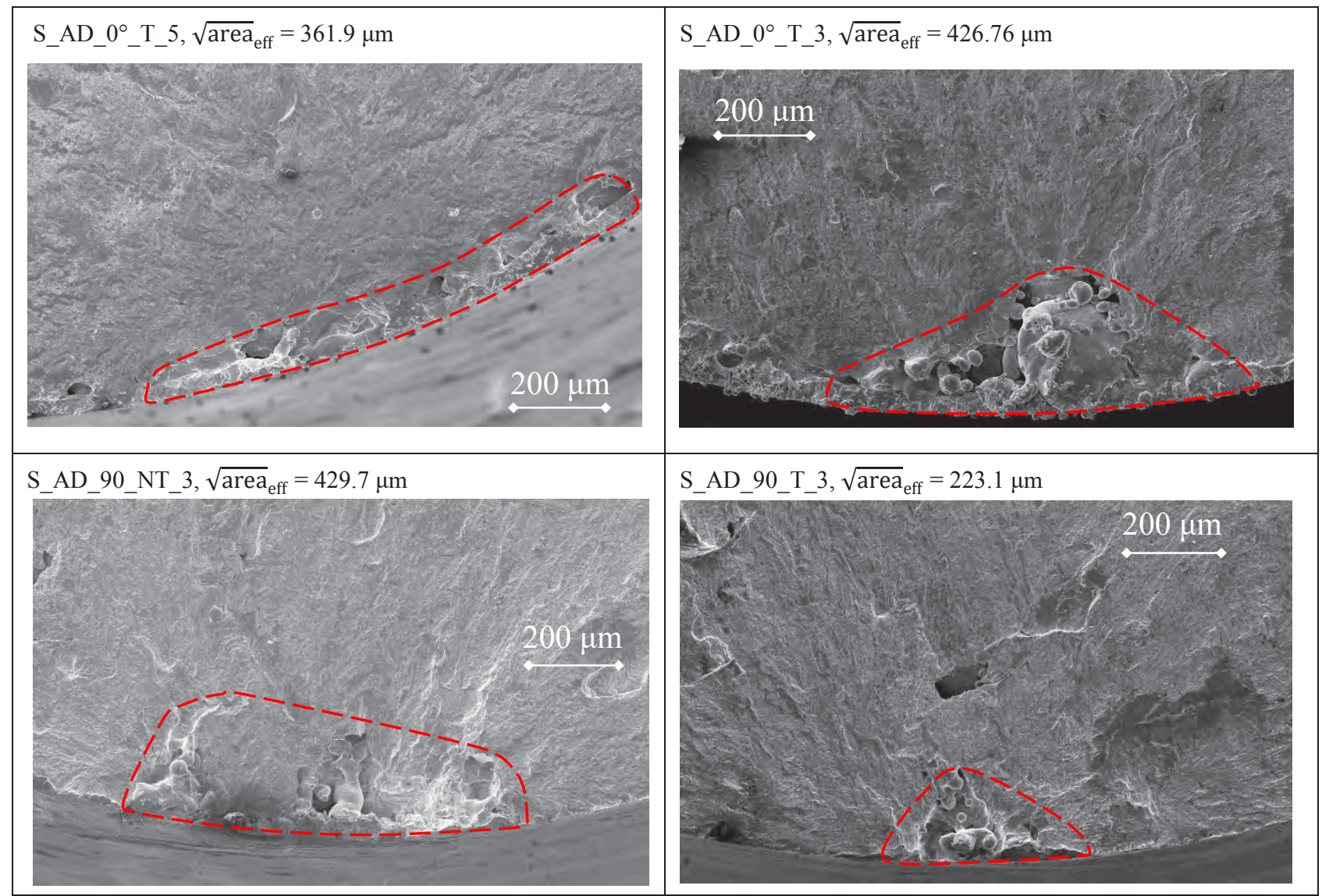

Figure 9 (continued).

Both batches are divided in four test series by taking into account the build orientation and heat treated/as-built condition (see Table 3 ).

As observed on the specimen related to the (E) batch, geometrical distortion caused by residual stresses also occurred on the $(\mathrm{S})$ batch, with more relevance in specimens which were not heat treated (NT). While for the (E) batch tested in the previous work the effect of mean stress caused by geometrical distortion had to be taken into account in this contribution the specimens' gross sections were turned to avoid misalignments.

For comparing the two batches, fatigue test results were plotted in terms of SWT parameter. All the fatigue data related to $(\mathrm{S})$ batch show a fatigue strength lower than those related to (E) batch. Focusing on the single test series of the $(\mathrm{S})$ batch, the specimens oriented at $0^{\circ}$, both (NT) and (T), exhibit a fatigue strength from $45 \%$ to $60 \%$ higher than those oriented at $90^{\circ}$ (fatigue strength evaluated at 1 million cycles) in disagreement with the results of the (E) test series [19]. It is worth highlighting that the values of the micro-hardness obtained on (S) specimens heat treated are not in agreement with the (E) ones and those reported in literature.

The inspections of the fracture surfaces have demonstrated that the fatigue failures of the AM components are mainly caused by the defects, which in literature are referred to as Lack Of Fusion (LOF). In agreement with the literature, this kind of defects present an irregular shape and are mainly located both at the surface and at the sub surface area of the component. In the examples reported in Fig. 9, it can be observed that the effective area of the defects related to the $(\mathrm{E})$ batch are about 4 times smaller than those calculated for the (S) batch. In addition, at the crack initiation area, a cluster of small defects is often observed; one possible interpretation is to consider such cluster as a single defect having an effective area that circumscribes all defects, but such hypothesis has not been validated yet.

\section{References}

1. J.P. Kruth, B. Vandenbroucke, J. van Vaerenbergh, I. Naert, AFPR, S4, 2005.

2. L. Rännar, A. Glad, C. Gustafson, Rapid Prototyp. J. 13 (2007)

3. L.E. Murr, S.M. Gaytan, D.A. Ramirez, E. Martinez, J. Hernandez, K.N. Amato, P.W. Shindo, F.R. Medina, R.B. Wicker, J. Mater. Sci. Technol. 28 (2012).

4. J. Kranz, D. Herzog, C. Emmelmann, J. Laser Appl. 27 (2015).

5. H.D. Carlton, A. Haboub, G.F. Gallegos, D.Y. Parkinson, A.A. MacDowell, Mater. Sci. Eng. A. 651 (2016).

6. Z. Wang, T.A. Palmer, A.M. Beese, Acta Mater. 110 (2016).

7. D. Manfredi, F. Calignano, M. Krishnan, R. Canali, E. Paola, S. Biamino, D. Ugues, M. Pavese, P. Fino, Light Met. Alloy. Appl., InTech, (2014) 
8. M.J. Donachie, Titanium: A Technical Guide, 2nd Edition, (2000).

9. W. Xu, M. Brandt, S. Sun, J. Elambasseril, Q. Liu, K. Latham, K. Xia, M. Qian, Acta Mater. 85 (2015).

10. J.J. Lewandowski, M. Seifi, Metal Additive Manufacturing: A Review of Mechanical Properties, (2016).

11. P. Li, D.H. Warner, A. Fatemi, N. Phan, Int. J. Fatigue. 85 (2016)

12. A. Yadollahi, N. Shamsaei, Int. J. Fatigue. 98 (2017).

13. R. Konečná, G. Nicoletto, L. Bubenko, S. Fintová, Eng. Fract. Mech. 108 (2013).

14. G. Nicoletto, S. Maisano, M. Antolotti, F. Dall'Aglio, Procedia Struct. Integr. 7 (2017).

15. G. Nicoletto, Procedia Struct. Integr. 7 (2017).

16. H. Gong, K. Rafi, H. Gu, T. Starr, B. Stucker, Addit. Manuf. 1 (2014)

17. Y. (Yukitaka) Murakami, Metal fatigue: effects of small defects and nonmetallic inclusions, Elsevier, (2002).

18. S. Romano, A. Brückner-Foit, A. Brandão, J. Gumpinger, T. Ghidini, S. Beretta, Eng. Fract. Mech. 187 (2017).

19. G. Meneghetti, D. Rigon, D. Cozzi, W. Waldhauser, M. Dabalà, Procedia Struct. Integr. 7 (2017). 